\title{
Design of micro-vibration isolation system for a remote-sensing satellite payload using viscoelastic materials
}

\author{
M. Safarabadi ${ }^{*}$, H. Izi ${ }^{\text {a }}$ J. Haghshenas ${ }^{\text {b }}$ and H. Koochaki Kelardeh
}

${ }^{a}$ Advanced Composites \& Nanocomposites Research (ACNR) Lab, School of Mechanical Engineering, College of Engineering, University of Tehran, Tehran, Iran

${ }^{b}$ Satellite Research Institute (SRI), Iranian Space Research Center (ISRC), Tehran, Iran ${ }^{c}$ Max Planck Institute for the Physics of Complex Systems, Germany

\begin{tabular}{|c|c|}
\hline A R T I C L EI N F O & A B S T RA C T \\
\hline $\begin{array}{l}\text { Article history: } \\
\text { Received } 8 \text { July, } 2019 \\
\text { Accepted } 22 \text { August } 2019 \\
\text { Available online } \\
22 \text { August } 2019\end{array}$ & $\begin{array}{l}\text { When a satellite is in orbit, micro vibration generated by its actuators (such as reaction wheels, } \\
\text { deployable mechanisms, etc.) will affect the imaging quality of the camera. Viscoelastic materials } \\
\text { are utilized as passive isolators to reduce these micro vibrations due to their simple construction } \\
\text { and excellent energy dissipation capacity, A finite element model of the entire satellite as well as }\end{array}$ \\
\hline $\begin{array}{l}\text { Keywords: } \\
\text { Reaction Wheel Disturbances } \\
\text { Micro-Vibration Isolation } \\
\text { Passive Control } \\
\text { Viscoelastic Materials }\end{array}$ & $\begin{array}{l}\text { as the sources of micro-vibrations and their forces are added to the model. To isolate these } \\
\text { vibrations, four square sorbothane pads are designed and added in the finite element model as } \\
\text { viscoelastic dampers located under the camera, between the camera and satellite bus. The } \\
\text { generalized Maxwell model is employed to describe the dynamic properties of the viscoelastic } \\
\text { elements in the ABAQUS software. Finally, by analyzing and comparing the dynamic responses } \\
\text { of the system with and without the viscoelastic sorbothane pads, it is realized that this isolation } \\
\text { system can effectively reduce the reaction wheel micro-vibrations on the camera and subsequently } \\
\text { increase the image quality. }\end{array}$ \\
\hline
\end{tabular}

(C) 2020 Growing Science Ltd. All rights reserved.

\section{Introduction}

With the fast development of remote sensing technology, the high quality and high resolution imaging of spacecraft systems has become a substantial issue in the world. During photographing of the in-orbit satellite, micro-vibrations, caused by motion of the moving parts, such as reaction wheels, solar array drive motors, and cryo-coolers, can seriously degrade the image quality. Despite the fact that it is not responsible for damage to the structure of the satellite, mico-vibration will affect the pointing accuracy and stability of high resolution satellite (Lee et al. 2015). Reaction wheels are commonly used to control the attitude of a satellite and consist of a rotating flywheel suspended on ball bearings encased in a housing and driven by an internal brushless DC motor (Bialke, 1998). Owing to the rotor imbalance, static imbalance, driving motor error, bearing defects and other factors, the reaction wheel assemblies (RWAs) will generate harmonic disturbance, which makes the reaction wheel become one of the key sources of micro-vibrations (Lee et al., 2015).

During the past few decades, researchers and engineers have developed several micro-vibration isolators for reducing micro-vibrations emitted by reaction wheels. Vaillon and Philippe (1999) designed and tested an elastomer-based passive vibration isolator for reducing micro-vibrations onboard. Webster et al. (2005) has designed and analyzed an effective rotational vibration absorption and isolation system for use in space borne remote sensing. Oh et al. (2005; 2006) designed and fabricated a variable-damping bio-metal fiber value isolator and conducted dynamic tests on the isolator using a flywheel.

* Corresponding author.

E-mail addresses: msafarabadi@ut.ac.ir (M. Safarabadi) 
Marneffe et al. (2009) proposed and analyzed a six-axis electromagnetic vibration isolation system for space precision payloads. Kamesh et al. (2010) designed a passive and active low-frequency platform for attenuating micro-vibrations, and also investigated passive control of this platform experimentally (Kamesh et al. 2012). Zhang et al. (2014) proposed a novel vibration isolation system for the reaction wheel using negative stiffness structures and multi tuned-mass dampers. Wei et al. (2015) proposed a vibration isolation platform by connecting four identical zig-zag beams symmetrically to a circular plate. Lee et al. (2016) experimentally studied the Stewart platform formed by multi hybrid vibration isolators. Wang et al. (2016) experimentally and numerically studied a passive and active hybrid isolation system constructed with springs, oil-filled corrugated pipes, and an inertial actuator. $\mathrm{Xu}$ et al. (2016) proposed a vibration isolation platform using vibration and mitigation devices. Deng et al. (2017) has used a rubber shock absorber in the satellite system to reduce the effect of micro vibration of the flywheel on the camera imaging system. They have also designed and installed a metal-rubber shock absorber in a real satellite to improve the image quality of space cameras.

It can be seen that the techniques of these micro-vibration isolation system can be classified into three main categories, e.g., passive, active, semi-active isolation (Liu, Jing, Daley, \& Li, 2015). The active and semi-active isolators can efficiently be used to reduce micro-vibrations, but their constructions are complex and accessories are needed to generate magnetic or electric fields. Viscoelastic (VE) dampers are among the earliest types of passive control devices that have been effectively utilized to solve dynamic problems in many fields, including space applications. Thanks to their advantages of simple construction, easy manufacturing process, low cost and excellent energy dissipation capacity, viscoelastic micro-vibration dampers have been developed to attenuate micro-vibrations (Darabi et al., 2016; Rao, 2003; Soong \& Spencer, 2002; Xu et al., 2016). Sorbothane is a viscoelastic polymer (polyurethane) that has low transmissibility verifying a high damping coefficient over a very wide temperature range compared to any other polymer (Sorbothane, 2015a). Sorbothane shows a nonlinear behavior that is a great advantage to isolation. It has relatively high damping at low frequencies, which allows resonant points to be controlled, and lower damping at higher frequencies, which results in better isolation at higher frequencies (Webster \& Semke, 2005). In this paper, small square Sorbothane pads are designed as viscoelastic isolators located under the camera, between the camera and satellite bus to reduce the effects of reaction wheel micro-vibrations on the camera and provide higher image quality.

\section{Viscoelastic Material Modeling}

Viscoelastic materials exhibit a mixture of purely elastic and purely viscous behavior. Owing to the nature of viscoelasticity, the properties of these materials are dependent on frequency. This is a big advantage of using these materials as a damper to isolate vibrations. At low frequency, the material tends to have an elastic behavior while at high frequencies, a viscoelastic rubber seems to become rigid (Jones, 2001). The properties of viscoelastic materials are commonly modeled in the complex domain. The dynamic complex modulus, $E^{*}$, and the loss factor, $\eta$, are given in frequency domain by Eqs. (1) and (2) (Brinson, 2015):

$$
\begin{aligned}
& E^{*}=E^{\prime}(\Omega)+i E^{\prime \prime}(\Omega)=E^{\prime}(\Omega)(1+i \eta), \\
& \eta=\frac{E^{\prime \prime}(\Omega)}{E^{\prime}(\Omega)}
\end{aligned}
$$

where $\Omega$ is the circular frequency of loading in radians/sec. The loss factor is a dimensionless parameter that is used to represent the extent of internal damping of viscoelastic materials. The real part of the modulus, $E^{\prime}$, called the storage modulus, is associated with the elastic behavior of the material and the imaginary part, $E^{\prime \prime}$, called the loss modulus, describes the material's viscous behavior. In small displacement, the linear viscoelasticity assumption is acceptable and the generalized Maxwell model (Prony series) can be used to describe the properties of the viscoelastic materials. In this model several Maxwell elements are assembled in parallel to an extra spring to represent the long-term (or equilibrium) modulus, $E_{\infty}$, as shown in Fig. 1 (Chae et al. 2010). Then, the storage-and-loss moduli are given by Eqs. (3-4) (Brinson, 2015):

$$
\begin{aligned}
& E^{\prime}(\Omega)=E_{\infty}+E_{0} \sum_{1}^{N} \frac{e_{i} \Omega^{2} \tau_{i}^{2}}{1+\tau_{i}{ }^{2} \Omega^{2}} \\
& E^{\prime \prime}(\Omega)=E_{0} \sum_{1}^{N} \frac{e_{i} \Omega \tau_{i}}{1+\tau_{i}{ }^{2} \Omega^{2}}
\end{aligned}
$$

where $E_{0}=\lim _{t \rightarrow 0} E(t)$ is the relaxed modulus, $E_{\infty}=\lim _{t \rightarrow \infty} E(t)$ is the long-term modulus, and the coefficients $e_{i}$ and $\tau_{i}$ are the material parameters (i.e., properties), and their relationships between them are given by Eq. (5) and Eq. (6):

$$
\begin{aligned}
& E_{i}=e_{i} E_{0} \quad i=1,2,3, \ldots, N \\
& E_{\infty}=E_{0}-\sum_{1}^{N} E_{i}
\end{aligned}
$$




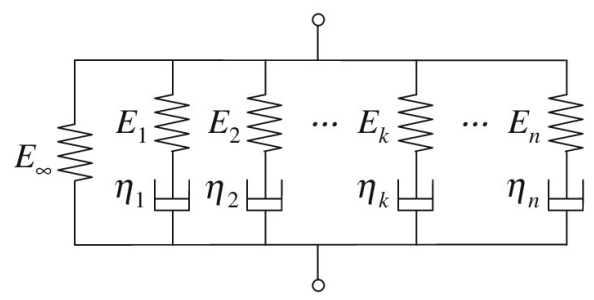

Fig. 1. Schematic of a generalized Maxwell model

Using the storage and loss moduli frequency-dependent data provided by the manufacturer, the parameters of Prony series can be recovered. Here, small displacements were assumed and the parameters of the Prony series were evaluated corresponding to durometer 30 Sorbothane at $23^{\circ} \mathrm{C}$ (Sorbothane, 2015c), presented in Table 1, and subsequently used in the FE software ABAQUS.

Table 1. The evaluated parameters of prony series for Sorbothane (Durometer 30)

\begin{tabular}{ccccccccc}
$\boldsymbol{E}_{\mathbf{0}}$ [MPa] & $\boldsymbol{E}_{\infty}$ [MPa] & $\boldsymbol{e}_{\mathbf{1}}$ & $\boldsymbol{e}_{\mathbf{2}}$ & $\boldsymbol{e}_{\mathbf{3}}$ & $\boldsymbol{\tau}_{\mathbf{1}}$ & $\boldsymbol{\tau}_{\mathbf{2}}$ & $\boldsymbol{\tau}_{\mathbf{3}}$ \\
$\mathbf{2 8}$ & 0.3 & 0.71 & 0.12 & 0.1 & 0.0012 & 0.01 & 0.072 \\
\hline
\end{tabular}

\section{Finite Element Modeling}

The finite element model of the whole satellite was constructed using the ABAQUS software as shown in Fig. 2. The model comprised 33893 nodes and 21856 elements and had no displacement constraints.

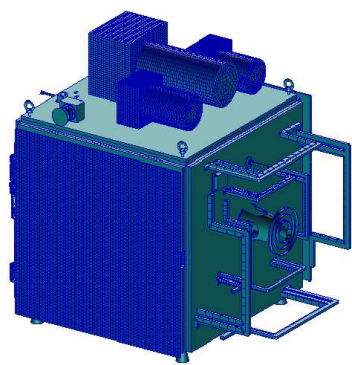

Fig. 2. The finite element model of the satellite

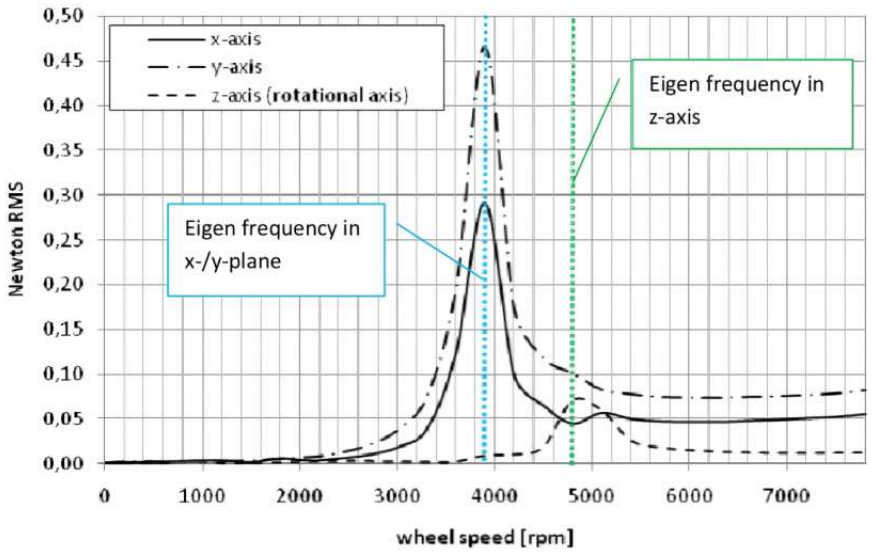

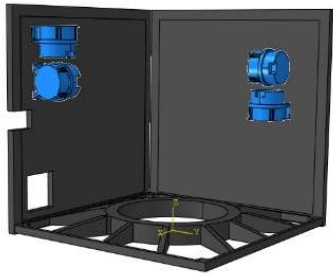

Fig. 3. Positions of reaction wheels

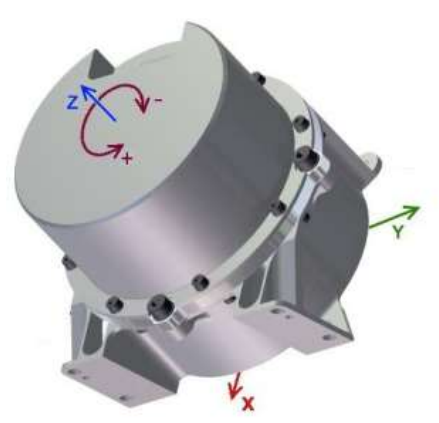

Fig. 4. Maximum force amplitudes at different wheel speeds

Four reaction wheels were included in the finite element model as the sources of micro-vibrations. Fig. 3 shows the positions of these reaction wheels. Technical specifications of these reaction wheels were selected from the RW 90 data sheet ("Enhanced technical specification of RW 90," 2011). The forces and moments model of the reaction wheels were added in the FE model. Fig. 4 presents maximum force amplitudes at different wheel speeds ("Enhanced technical specification of RW 90," 2011). Apparently, forces will not exceed $0.05 \mathrm{~N}$ at wheel speeds less than $3000 \mathrm{rpm}$. In this range, dominant vibration frequencies correspond to the particular Eigen frequencies of 65 and $80 \mathrm{~Hz}$ respectively. At very low wheel speeds, less than 
$1000 \mathrm{rpm}$, forces even fall below 0.005 Newton. To isolate micro-vibrations, two geometric cases were considered as viscoelastic dampers located under the camera. In the case 1, four small square Sorbothane pads were added in the finite element model as shown in Fig. 5. The dimensions of the pads were chosen so that they are able to endure the weight of the camera in normal gravitational conditions (Sorbothane, 2015b). The length, width and thickness of the pads are $2.54,2.54$ and $0.6 \mathrm{~cm}$ respectively. In the case 2, one large square Sorbothane pad was used as shown in Fig. 6.

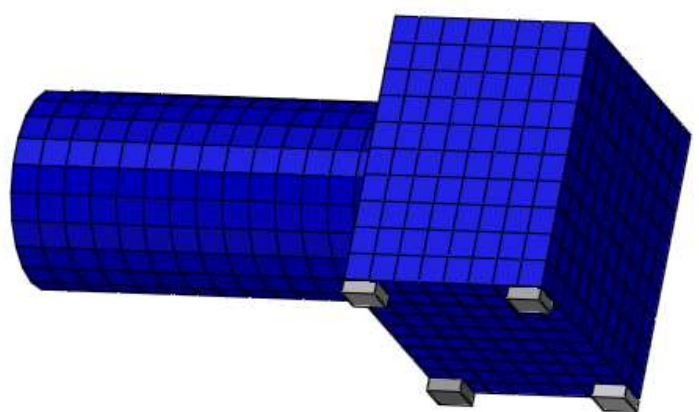

Fig. 5. Case 1. Four small square pads under the camera

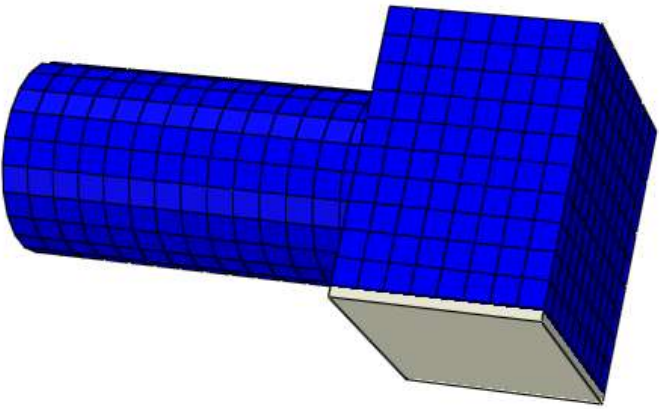

Fig. 6. Case 2. one large square pad under the camera

\section{Results and discussion}

As mentioned in introduction part, the imbalance excitations are the major disturbances induced by the reaction wheels. Here, these excitations were employed as external excitations and the dynamic responses of the system with and without the Sorbothane pads were analyzed and compared. It should be noted that this isolation system is designed for the camera on satellite in a zero gravity environment and the static deflections due to the weight of the camera are ignored. The coordinate system is also shown in Fig 7.
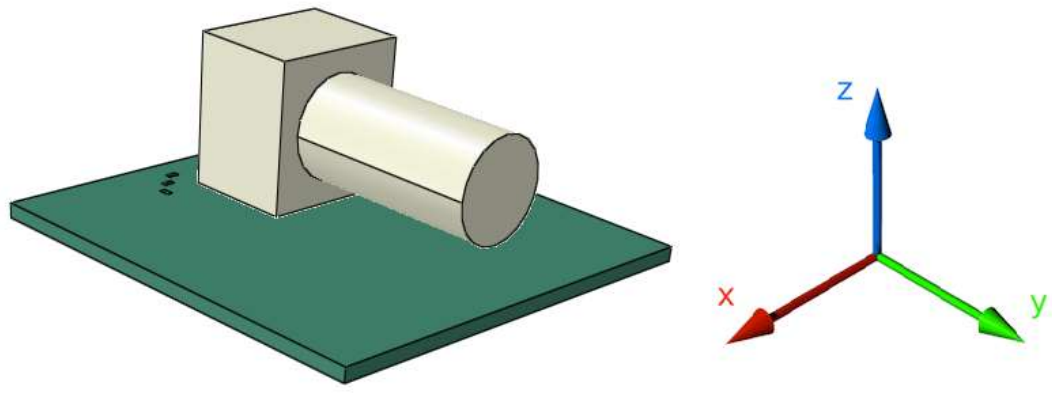

Fig. 7. The coordinate system

Fig. 8 shows the linear acceleration amplitudes of the camera at different wheel speeds in xyz-directions with and without the Sorbothane isolation pads. Here, wheel speeds mean excitation frequencies, and vice versa. It can be seen that according to the position and configuration of reaction wheels, the maximum acceleration amplitude of the camera occurs in $\mathrm{x}$-direction. Moreover, in all directions, the maximum acceleration of the camera appears at the wheel speed of $3900 \mathrm{rpm}(65 \mathrm{~Hz})$,the Eigen frequency of each reaction wheel, and the isolation system has been excellently able to reduce these disturbances by $98 \%, 99.2 \%$, and $99.5 \%$ in $\mathrm{x}, \mathrm{y}$, and z-direction, respectively.

To study the performance of the isolation system for the camera in frequency domain, the transmissibility of the isolation pads is defined as the ratio of the transmitted force to the input force and it is plotted for the Sorbothane pads in Fig. 9. The results show that, at low wheel speeds, the isolation performance of the Sorbothane pads is slight, and the force transmitted to the camera is amplified in $\mathrm{x}$ and $\mathrm{y}$-direction. This is because the excitation frequency meets the resonant point, $2 \mathrm{~Hz}$. However, at high wheel speeds, the isolation effects are excellent since the excitation frequencies are far from the resonant point. This amplification phenomenon, which occurs around the resonance frequency of the isolators, is unavoidable for the passive isolation system, and generally, the isolation performance is better if the resonance frequency of the isolator is lower. The amplification phenomenon is never seen in the direction of perpendicular to the pads, z-direction. 


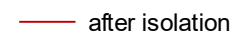

before isolation

(a)
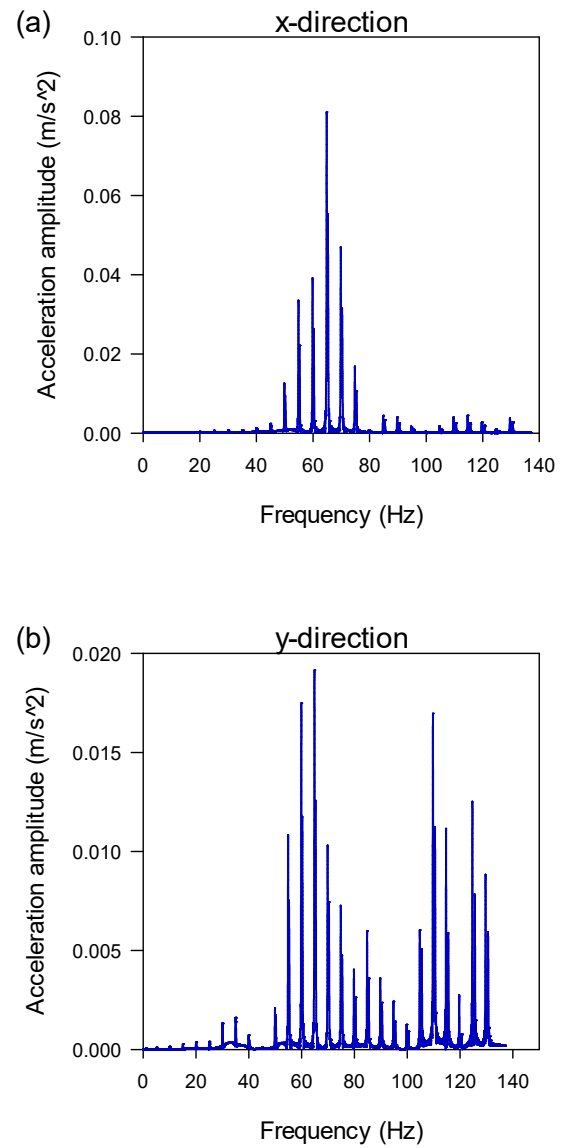

(c)

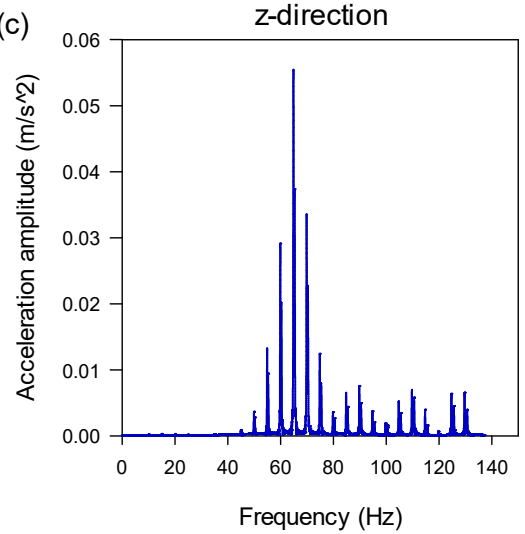

(d)

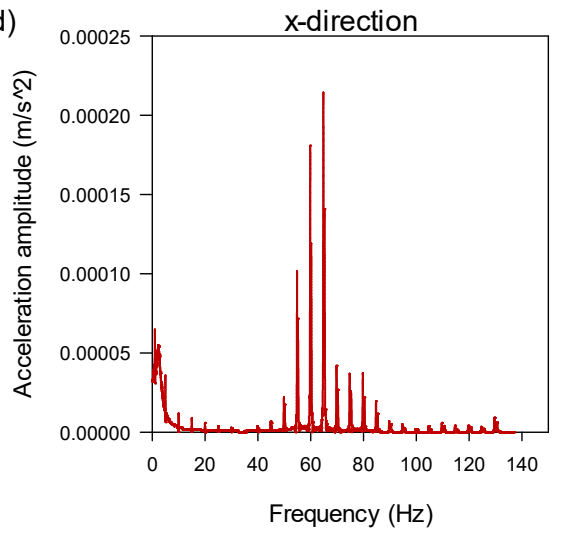

(e)

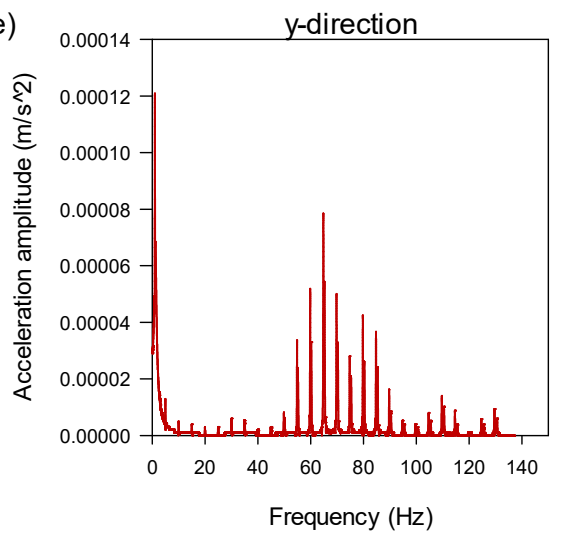

(1)

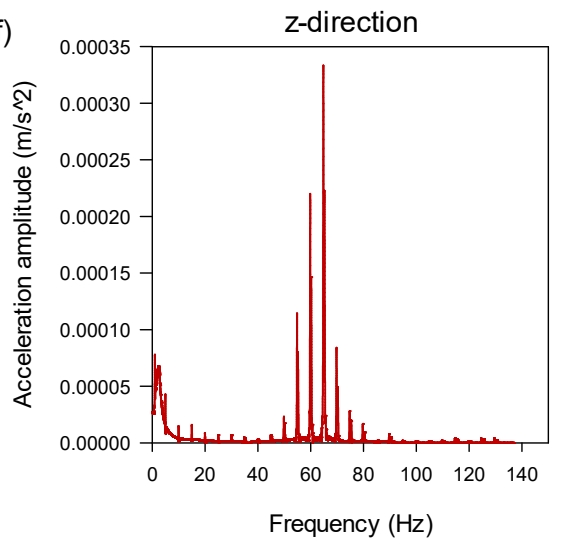

Fig. 8. The acceleration amplitudes of the camera at different wheel speeds in xyz-directions: (a, b, c) before isolation; (d, e, f) after isolation 


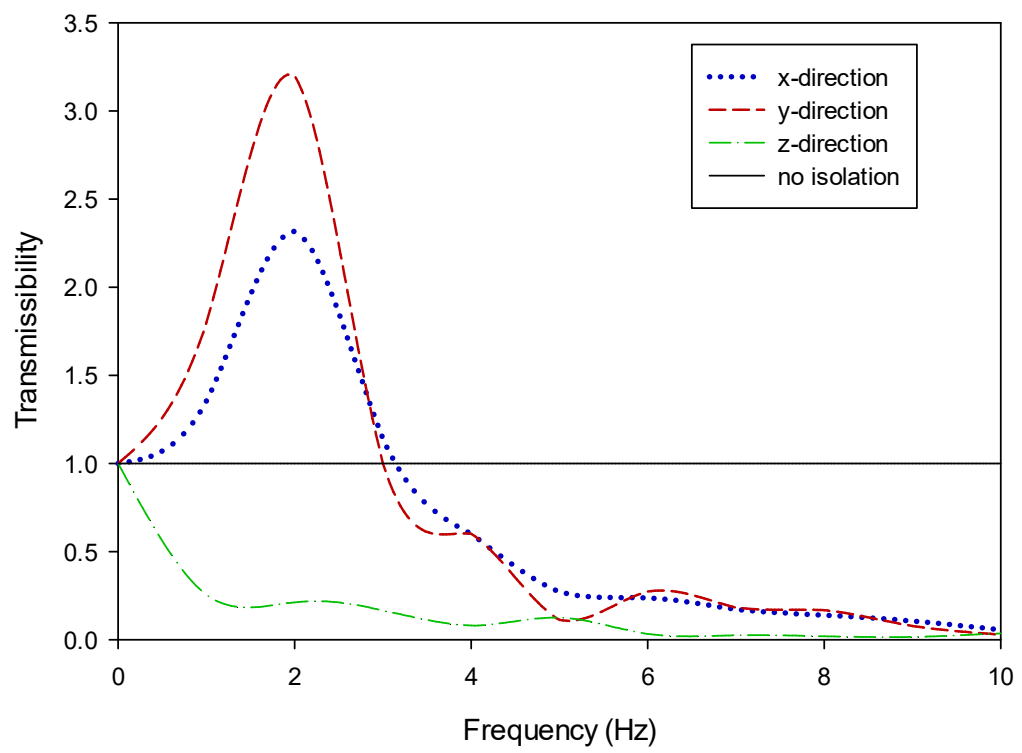

Fig. 9. The transmissibility of the Sorbothane pads versus excitation frequency

Fig. 10 compares the transmissibility of the Sorbothane pads and the natural rubber pads in x-direction, in which the maximum force amplitudes exist. Owing to the higher loss factor of the Sorbothane pads, they have lower transmissibility and better performance in comparison to the natural rubber pads. Fig. 11 compares the transmissibility of the system in two considered cases and shows that designed system in the case 1 has lower transmissibility and lower resonance frequency and as a result, better isolation performance compared to the case 2 .

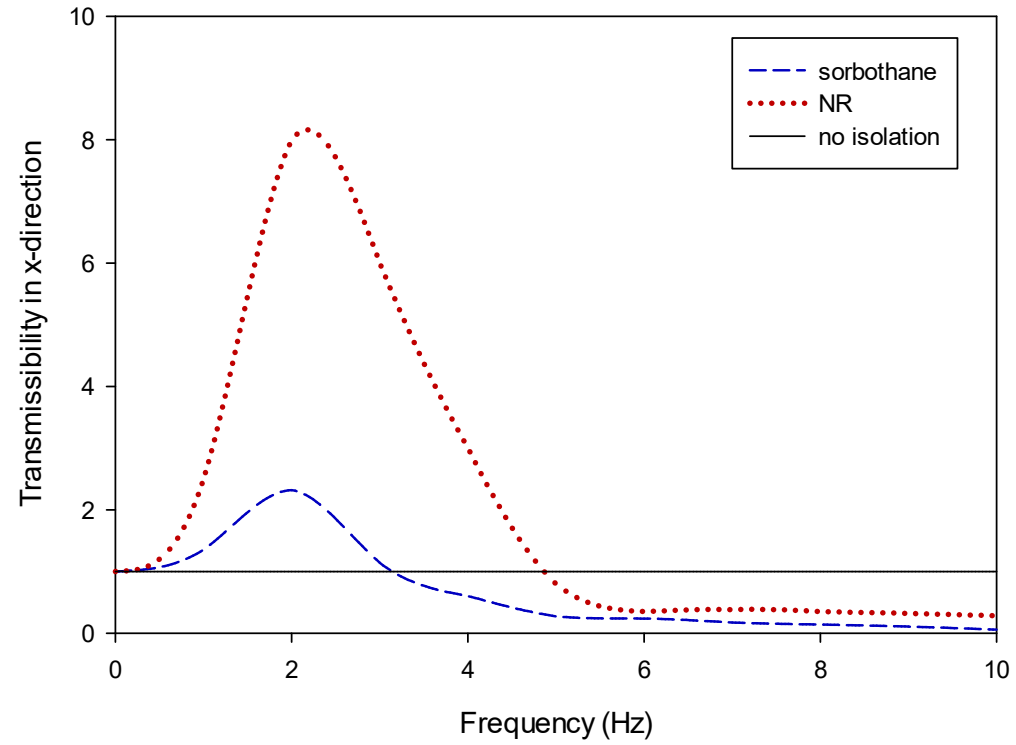

Fig. 10. Comparison between the transmissibility of the Sorbothane pads and the transmissibility of the Natural Rubber pads 


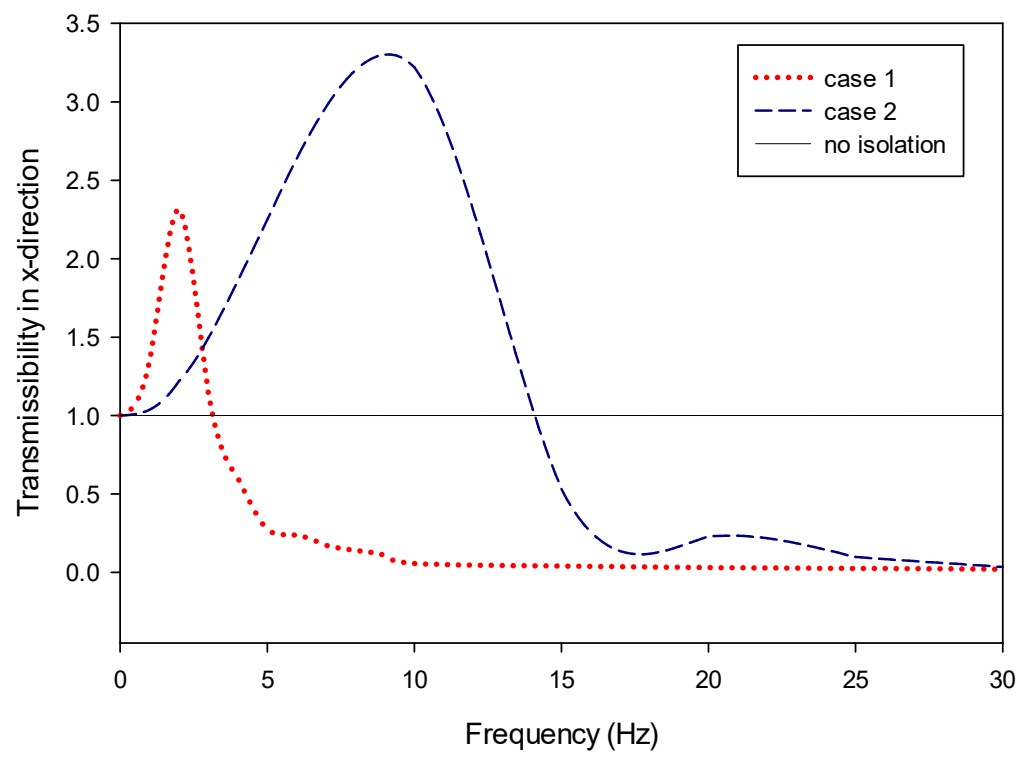

Fig. 11. Comparison between the transmissibility of two geometric cases in $x$-direction

\section{Conclusion}

In this paper, a viscoelastic micro-vibration isolation system is proposed, which uses Sorbothane, a high-damping viscoelastic material, to reduce the effects of the reaction wheel disturbances on the camera. Square Sorbothane pads are designed and modeled between the camera and satellite bus. The viscoelastic model, generalized Maxwell, is employed to describe the dynamic properties of durometer 30 Sorbothane in the ABAQUS software. By analyzing and comparing the dynamic responses of the system with and without the viscoelastic Sorbothane pads, some conclusions can be obtained, as follows:

1. The dynamic properties of Sorbothane are dependent on the excitation frequency. At low frequencies, the isolation performance of the Sorbothane pads is slight, and the responses are even amplified at some conditions, around the resonant point. However, at high frequencies, the isolation effects are excellent.

2. Sorbothane has lower transmissibility and better performance in comparison to the other elastomers like natural rubber.

3. Four small Sorbothane pads have better isolation performance than one large Sorbothane pad.

4. The viscoelastic micro-vibration isolation system can effectively reduce disturbances and has good isolation effects under different excitations, especially in the high-frequency range.

\section{References}

Bialke, B. (1998). High Fidelity Mathematical Modeling of Reaction Wheel Performance. 21st Annual American Astronautical Society Guidance and Control Conference.

Brinson, H. F., Brinson, L., \& Catherine. (2015). Polymer Engineering Science and Viscoelasticity : An Introduction: Springer-Verlag New York Inc.

Chae, S.-H., Zhao, J.-H., Edwards, D., \& Ho, P. (2010). Characterization of the Viscoelasticity of Molding Compounds in the Time Domain (Vol. 39).

Darabi, B., Rongong, J. A., \& Zhang, T. (2016). Viscoelastic granular dampers under low-amplitude vibration. Journal of Vibration and Control, 24(4), 708-721. doi:10.1177/1077546316650098

deng, C., Mu, D., An, Y., Yan, Y., \& Zongxuan, L. (2017). Reduction of satellite flywheel microvibration using rubber shock absorbers (Vol. 19).

Deng, C., Mu, D., Guo, J., \& Xie, P. (2017). Reducing the negative effects of flywheel disturbance on space camera image quality using the vibration isolation method. Frontiers of Optoelectronics, 10(1), 80-88. doi:10.1007/s12200-017-0665-0

Enhanced technical specification of RW 90. (2011). Astround Feinwerktechnic Adlershof GmbH.

Jones, D. I. G. (2001). Handbook of Viscoelastic Vibration Damping: Chichester ; New York : J. Wiley.

Kamesh, D., Pandiyan, R., \& Ghosal, A. (2010). Modeling, design and analysis of low frequency platform for attenuating micro-vibration in spacecraft. Journal of Sound and Vibration, 329(17), 3431-3450. 
Kamesh, D., Pandiyan, R., \& Ghosal, A. (2012). Passive vibration isolation of reaction wheel disturbances using a low frequency flexible space platform. Journal of Sound and Vibration, 331(6), 1310-1330.

Lee, D.-O., Park, G., \& Han, J.-H. (2015). Experimental study on on-orbit and launch environment vibration isolation performance of a vibration isolator using bellows and viscous fluid. Aerospace Science and Technology, 45, 1-9.

Lee, D.-O., Park, G., \& Han, J.-H. (2016). Hybrid isolation of micro vibrations induced by reaction wheels. Journal of Sound and Vibration, 363, 1-17.

Liu, C., Jing, X., Daley, S., \& Li, F. (2015). Recent advances in micro-vibration isolation. Mechanical Systems and Signal Processing, 56-57, 55-80.

Marneffe, B. D., Avraam, M., Deraemaeker, A., Horodinca, M., \& Preumont, A. (2009). Vibration Isolation of Precision Payloads: A Six-Axis Electromagnetic Relaxation Isolator. Journal of Guidance, Control, and Dynamics, 32(2), 395-401. doi:10.2514/1.39414

Oh, H.-U., Izawa, K., \& Taniwaki, S. (2005). Development of variable-damping isolator using bio-metal fiber for reaction wheel vibration isolation (Vol. 14).

Oh, H.-U., Taniwaki, S., Kinjyo, N., \& Izawa, K. (2006). Flywheel vibration isolation test using a variable-damping isolator (Vol. 15).

Rao, M. D. (2003). Recent applications of viscoelastic damping for noise control in automobiles and commercial airplanes. Journal of Sound and Vibration, 262(3), 457-474.

Soong, T. T., \& Spencer, B. F. (2002). Supplemental energy dissipation: state-of-the-art and state-of-the-practice. Engineering Structures, 24(3), 243-259.

Sorbothane. (2015a). Data sheet 102, performance curves. https://www.sorbothane.com/Data/Sites/31/pdfs/data-sheets/102Sorbothane-performance-curves.pdf

Sorbothane. (2015b). Isolation pads, Materrial Property Data. https://www.sorbothane.com/Data/Sites/31/pdfs/productguides/sorbothane-spg-isolation-pads.pdf

Sorbothane. (2015c). Data sheet 101, Material Properties of Sorbothane. http://www.sorbothane.com/Data/Sites/31/pdfs/data-sheets/101-sorbothane-material-properties.pdf

Vaillon, L., \& Philippe, C. (1999). Passive and active microvibration control for very high pointing accuracy space systems. Smart Materials and Structures, 8(6), 719.

Wang, C., Chen, Y., \& Zhang, Z. (2016). Simulation and experiment on the performance of a passive/active micro-vibration isolator. Journal of Vibration and Control, 24(3), 453-465.

Webster, A. L., \& Semke, W. H. (2005). Broad-band Viscoelastic Rotational Vibration Control for Remote Sensing Applications. Modal Analysis, 11(11), 1339-1356. doi:10.1177/1077546305057222

Wei, Z., Li, D., Luo, Q., \& Jiang, J. (2015). Modeling and analysis of a flywheel microvibration isolation system for spacecrafts. Advances in Space Research, 55(2), 761-777.

$\mathrm{Xu}$, C., Xu, Z.-D., Ge, T., \& Liao, Y.-X. (2016). Modeling and experimentation of a viscoelastic microvibration damper based on a chain network model (Vol. 11).

Xu, C., Xu, Z.-D., Huang, X.-H., Xu, Y.-S., \& Ge, T. (2017). Modeling and analysis of a viscoelastic micro-vibration isolation and mitigation platform for spacecraft. Journal of Vibration and Control, 24(18), 4337-4352. doi:10.1177/1077546317724321

Zhang, Y., Guo, Z., He, H., Zhang, J., Liu, M., \& Zhou, Z. (2014). A novel vibration isolation system for reaction wheel on space telescopes. Acta Astronautica, 102, 1-13.

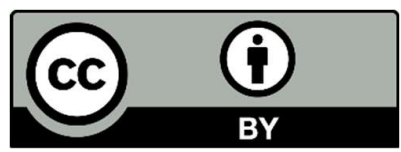

(C) 2020 by the authors; licensee Growing Science, Canada. This is an open access article distributed under the terms and conditions of the Creative Commons Attribution (CC-BY) license (http://creativecommons.org/licenses/by/4.0/). 